\title{
Prevalence and Management Practices of Lumpy Skin Disease (LSD) in Cattle at Natore District of Bangladesh
}

\author{
Md. Hakimul Haque, Rahul Krishna Roy, Farhana Yeasmin, Md. Fakhruzzaman, Tanjina Yeasmin, \\ Md. Rabiul Islam Sazib, Md. Nasir Uddin, and Subir Sarker
}

\section{ABSTRACT}

Lumpy skin disease (LSD) is a potentially contagious viral disease in cattle, caused by the Lumpy skin disease virus (LSDV), which belongs to the family Poxviridae. The virus is suspected to spread via biological vectors such as mosquitoes, flies, ticks, and direct contact. It is a significant economic disease caused by a virus that causes significant losses in milk production, fertility, abortions, import restrictions, and, in some cases, death in the livestock animals. This study aimed to assess the current state of LSD and its management on several farms in the north-western region of Bangladesh. Data were obtained from two Upazilas in the Natore district (Natore Sadar and Baraigram) using a structured questionnaire. During the study period of 1 June to 20 December 2020, a total of 34 small farms and 87 animals were monitored. The OIE guidelines directed the diagnosis of LSD based on current clinical indicators. MS Excel and SPSS statistical software were used to evaluate all of the data. Morbidity, mortality, and case-fatality rates were found to be $64.70 \%, 2.94 \%$, and $4.53 \%$ in Natore Sadar and 83.02 \%, 3.77 \%, and 4.55 \% in Baraigram Upazilas, respectively. Female animals that were newly matured (2-4 years) were a larger prone to LSD infection $(\mathbf{4 3 . 1 \%})$ than animals of other ages. A total of $34.43 \%$ illness was found in young bull cattle aged (2-4). Bull and heifer calves are also vulnerable populations, with reports of LSD infection leading to mortality. Limb swelling is a common clinical symptom, and LSD-positive young mature (2-4 year) cattle had the most significant rate $(\mathbf{1 8 . 3 9 \%})$ of limb swelling. The farm hygiene practice is a critical determinant in the spread of LSDV, and a large proportion of cattle (48.27 $\%$ ) infected with LSD were on farms with poor hygienic management, compared to good $(01.14 \%)$ and medium $(01.14 \%)$ hygienic management practices $(26.43 \%)$. Despite the fact that mosquito nets help prevent mosquitoes, most owners $(91.17 \%)$ did not use one in their cattle barn at night. More study is needed in Bangladesh to improve the clinical management of LSD, identify risk factors, and understand the molecular characteristics of diseases.

Keywords: LSD, mosquitoes, morbidity, mortality, case fatality, hygienic management, Poxviridae.

Submitted : November 24, 2021

Published : December 16, 2021

ISSN: $2684-1827$

DOI: 10.24018 /ejfood.2021.3.6.420

Md. Hakimul Haque*

Faculty of Veterinary and Animal

Sciences, University of Rajshahi,

Rajshahi-6205, Bangladesh.

(e-mail: hakim.ahvs@ru.ac.bd)

Rahul Krishna Roy

Faculty of Veterinary and Animal

Sciences, University of Rajshahi,

Rajshahi-6205, Bangladesh.

(e-mail: dvmrahul1994@gmail.com)

Farhana Yeasmin

Faculty of Veterinary and Animal

Sciences, University of Rajshahi, Rajshahi-6205, Bangladesh.

(e-mail: farhanamituru10@gmail.com)

Md. Fakhruzzaman

Faculty of Veterinary and Animal

Science, Hajee Mohammad Danesh

Science and Technology University

(HSTU), Dinajpur-5200, Bangladesh.

(e-mail: fakhrul.hstu@gmail.com)

Tanjina Yeasmin

Faculty of Veterinary and Animal Sciences, University of Rajshahi, Rajshahi-6205, Bangladesh.

(e-mail: tanijnatoma111@gmail.com)

Md. Rabiul Islam Sazib

Faculty of Veterinary and Animal Sciences, University of Rajshahi, Rajshahi-6205, Bangladesh.

(e-mail: robiulsazib475@gmail.com) Md. Nasir Uddin

Faculty of Veterinary and Animal Sciences, University of Rajshahi, Rajshahi-6205, Bangladesh.

(e-mail: nasirnahid4@gmail.com)

Subir Sarker

Department of Physiology, Anatomy and Microbiology, School of Life Sciences, La Trobe University, Melbourne, VIC 3086, Australia.

(e-mail: s.sarker@latrobe.edu.au)

*Corresponding Author

\section{INTRODUCTION}

In many developing global regions, livestock raising is one of the most important ways to improve living standards [1]. The livestock industry is hugely active, accounting for $40 \%$ of global agricultural output and supporting nearly a million people's food security and livelihoods [2]. Farm animal husbandry is a multifaceted practice in many developing nations, including Bangladesh, and plays a significant role in the national economy and rural populations' livelihoods [3]. However, livestock farmers' incomes are threatened by a variety of animal ailments, including recent outbreak of lumpy skin disease [4]-[8]. LSD is a highly transmissible infection that primarily affects cattle. Also, it is prevalent in most African countries, with severe complications and poor fatality rates are recorded [9]. However, it has persisted in disseminating in the Middle East in recent years, and it is now a growing danger to the people of Eurasia [10]. Consequently, this disease 
considerably influences cattle ranching, especially in small farming, where financial losses force farmers to reduce their income and discourage agribusiness in society [11].

LSD) is caused by the LSDV, which belongs to the Capripoxvirus (CaPV) genus in the Poxviridae family. The genus Capripoxvirus includes three closely related significant animal virus species that infect sheep, goats, and cattle by sheeppox virus (SPV), goatpox virus (GPV), and LSDV, respectively [12]-[16]. All three CaPVs can only infect ruminants, and no zoonoses have been documented [17]. Surprisingly, even when kept close to infected cattle, the disease has not been detected in sheep or goats [9]. However, mechanical vectors such as biting flies and mosquitoes (Aedes aegypti) and three tick species, Rhipicephalus appendiculatus, Amblyomma hebraeum, and Rhipicephalus decoloratus, are the most prevalent carriers of this disease [18], [19]. LSD symptoms can range from mild to severe. There is currently no indication of virulence differences between the various LSDV strains [16]. Pyrexia with a 6-9-day incubation period, nodules $(2-5 \mathrm{~cm}$ in diameter) on mucosal surfaces and cutaneous, folliculitis, gastrointestinal and respiratory systems lesions, and enlargement of the superficial lymph nodes are all symptoms of LSD [20]. All fluids, ocular and nasal discharge and saliva contain LSDV when the nodules on the eyes, nose, mouth, rectum, udder mucous membranes, and genitalia ulcerate. The animal's limbs may be edematous, and it is hesitant to move. Cattle that are pregnant may abort, and there have been reports of intrauterine transmission [21]. Bulls can permanently become infertile or temporarily, and the virus can be expelled in the sperm for extended periods [22]. The animal is underweighted, may have pneumonia or mastitis, and the necrotic plugs of skin, which may have been prone to fly strike, are shed, leaving gaping holes in the hide [23].

Furthermore, depending on the situation, the incidence of LSD varies from 2 to $85 \%$ in different places. In endemic locations, the morbidity rate is typically reported at $10 \%$ [16]. Apart from this, LSDV affects cattle of all sexes and ages; however, some study suggests that young animals are particularly vulnerable to this deadly disease [24]. In general, mortality ranges from $1 \%$ to $3 \%$, but it can reach $40 \%$ in extreme cases [25]. Though the genesis of LSD is unknown, and it was once thought to be an African sickness, it is now seen in almost every country [25]. LSD's emergence is more rapid, with disastrous consequences, and its current dissemination to several Asian countries is posing a serious threat to the livestock industry [26]. LSD is classified as a notifiable disease by the World Organization for Animal Health (OIE) due to its rapid spread and significant economic effect. For the first time in 2019, an LSD outbreak was reported in Bangladesh 2019 [27], [28]. In 2019, LSD outbreaks in Bangladesh infected several cattle populations across the country, posing a new threat to livestock health. In 2020, LSD outbreaks were recorded in several parts of the country, where the disease is fast spreading in thousands of cattle, resulting in at least 50 deaths in Bangladesh's northern and north-eastern provinces [29]. Despite certain epidemiological and pathological investigations, there is a significant deficit in essential information on a district-by-district and country-by-country basis [30], [31]. As a result, the goal of this study was to look into the incidence of LSD in Bangladesh's Natore district and some of the concerns surrounding livestock management.

\section{MATERIALS AND METHODS}

\section{A. Description of the Study Area}

Natore is a Bangladeshi district in the northwestern part of the country, bordered by Rajshahi, Pabna, Sirajganj, Bogra, and Naogaon. The district is divided into seven Upazilas (subdistricts), with the Upazilas of Natore Sadar and Baraigram being chosen for this study. This district is famous for its convenient transportation and numerous wellknown cattle markets at Tebaria Haat in Natore Sadar Upazilas. The research areas are displayed in Figure 10. From June 1 to December 20, 2020, a study was done among 34 small household cattle producers in Natore Sadar and Baraigram Upazilas of Natore district, with a total of 87 $(\mathrm{N}=87)$ cattle observed.

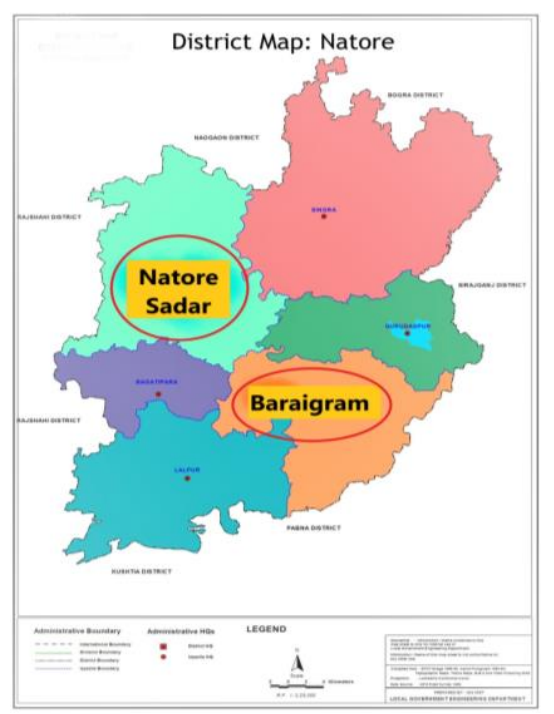

Fig. 1. Map of Natore district, Natore Sadar, and Baraigram Upazilas (the study areas).

\section{B. Farm Visit and Data Collecting}

A pre-structured questionnaire was employed during fieldwork to collect data. First, the investigator interviewed the owner or responsible person of each affected farm or family. In addition, the farm's demographic data included the total number of cattle, the percentage of LSD-affected animals, and the number of disease-related deaths. The age of the sick animal, sex, the type of animal (lactating cow, dry cow, pregnant heifer, calf, and bull), limb swelling, intra-herd farm hygiene, use of mosquito curtain, and any treatment were all recorded. Following that, our advised treatment procedure was followed. The OIE manual was used to match the characteristics of the skin lesions, which led to a provisional diagnosis of LSD.

\section{Rate of Morbidity}

The morbidity rate is the percentage of people in a given geographic area who contract a specific disease during a given time. It shows how frequently an illness appears in a population. The state of being ill or diseased is referred to as 
morbidity. Injury, sickness, and disability are all included in this category. Acute or chronic illness is possible. The rate of morbidity is expressed as a percentage.

$$
\text { Morbidity Rate }=\frac{\text { Number of Cases of Disease / Injury / Disability }}{\text { Population }} \times 100
$$

\section{Rate of Mortality}

A mortality rate is a measurement of how often people die in a given population during a given period. Mathematically, morbidity and mortality metrics are often the same; it's just a question of whether researchers want to assess disease or death. The formula for calculating the mortality of a specific population over a given period of time is as follows:

$$
\text { Morbidity Rate }=\frac{\text { Number of Cases of Death }(\text { Over a period of Time })}{\text { Population }} \times 10
$$

\section{E. Rate of Case-fatality}

The case-fatality rate is the percentage of people who are affected (cases) by a disease who die as a result of it. It is a metric for determining the severity of a condition. The formula is as follows:

$$
\text { Case }- \text { fatality Rate }=\frac{\text { Number of Cases of Death }}{\text { Total Number of Incident Cases }} \times 100
$$

\section{F. Management of Data and Statistical Analysis}

Descriptive analysis was conducted using Microsoft Office Excel and SPSS after gathering all data. A statistically significant value was defined as one with a probability value of less than 0.05 .

\section{RESULTS AND DISCUSSION}

LSD is a widespread disease of cattle in many parts of the world, notably in Africa, and affected cattle serve as a natural reservoir of infection for the virus [32]. It's a highly contagious virus that's costing the cattle business a lot of money. LSD was first recorded in numerous African and Middle Eastern countries and then spread to Europe. However, in 2019, the World Health Organization (WHO) acknowledged the presence of LSD across the Indian subcontinent, including India [33], China [34], and Bangladesh [27]. In Bangladesh, epidemiology data on LSD is currently lacking. As a result, the study's goal was to improve the data resources.

Using field study approaches, the prevalence and management of LSD were explored in two locations of northwest Bangladesh. Small nodules (15-45 $\mathrm{mm}$ ) developed across the whole-body surfaces of the suspected LSD cattle $(\mathrm{N}=87)$ in this investigation, primarily on the neck and trunk region. The nodules are raised and affect both the epidermis and dermis layers of the skin [30]. Epidermal microvesicles grew into giant vesicles that ruptured quickly, showing an ulcerated area infested with pathogens, causing bacterial pneumonia and secondary bacterial infection, tracheal stenosis, and mastitis [35]. The ulcerated nodules healed slowly, and the injured animals were typically incapacitated for months. The average rectal temperature ranged from 103 to $106.6^{\circ} \mathrm{F}$, with leg edema, particularly in the hock region, and mild lymphadenopathy [30]. Regional lymph nodes grew up to ten times their original size, edematous, congested, and infected with cellulitis [36].

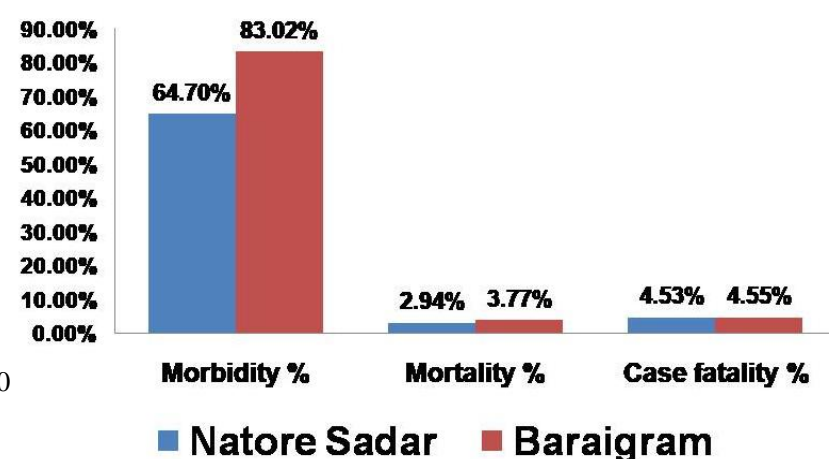

Fig. 1. The percentage of cattle's morbidity, mortality, and case fatality due to lumpy skin disease.

The morbidity rate reported previously in a range from 2 to $85 \%$ or even higher [30]. In this study, approximately $64.70 \%$ and $83.02 \%$ of cattle were affected with LSD in Natore Sadar and Baraigram Upazilas, respectively (Fig. 1). In contrast, Biswas et al. (2020) found $63.33 \%$ and $52.38 \%$ of cattle affected with LSD in Monirampur and Avoynagor Upazilas, respectively (Fig. 1) [30]. In Badalgachi, Naogaon, Haque, and Gofur (2020) observed a $49 \%$ incidence rate, while in Dinajpur, Bangladesh, Sarkar et al. showed $41.06 \%$ prevalence [31], [37]. On the other hand, Hasib et al. [38] showed $10 \%$ prevalence in commercial farms; with the most significant farm level outbreak frequency being $63.33 \%$ and the lowest was $4.22 \%$. Cattle breed, host vulnerability, herd immunological status, and insects/mechanical vectors involved in virus transmission influence morbidity and mortality [39]. Biting flies/mosquitoes, on the other hand, are the disease's top mechanical carriers, and their population rises from July to October in tropical nations like Bangladesh [40].

Despite fewer animals being evaluated and the study being shorter, the morbidity rates were within the expected range in this investigation. Morbidity rates in endemic areas are typically around $10 \%$, resulting in significant economic losses [41]. In Natore Sadar, however, the death rate was 2.94\%, while in Baraigram; it was $3.77 \%$ (Fig. 1). Biswas et al. [30], found $1.59 \%$ mortality in Abhaynagar, and 3.33 percent in Monirampur Upazila, Haque and Gofur [41] found $0.5 \%$, while prior research revealed $0.99-2.12 \%$ mortality [37], [42], [43]. In the endemic area, fatality rates ranged from $1 \%$ to $5 \%$. In epidemic areas, it can sometimes reach up to $40 \%$ [41]. According to the survey, the case fatality rate at Natore Sadar was $4.53 \%$ and $4.55 \%$ at Baraigram (Fig. 1). Biswas et al. [30], found a case fatality rate of $5.26 \%$ at Monirampur and $3.03 \%$ at Avoynagor, whereas Haque and Gofur [42] reported case fatality rate of $1 \%$. Although no economic analysis was performed in this study, it was noted that the financial distress caused by the draught power outage, treatment, and immunization costs, which totaled roughly 32 USD per animal, were significant. 
Female animals between the ages of two and four were more vulnerable to LSD infection $(43.1 \%)$ than animals of other ages (Table I). Young female animals (13-36 months) were more at risk of LSD infection (39.24\%) than other age groups, and that this vulnerability was substantially higher $(\mathrm{P}<0.05)$ than the early and older age groups [30]. Similarly, another study found that the age group of 5 years had the most significant frequency $(30 \%)$ of LSD. In contrast, the age groups of $0-1$ year and 2-3 years had the moderate and lowest frequencies, respectively. Females were more likely infected by LSD $(34.8 \%)$ than males. A similar finding was observed in a Ugandan sero-prevalence study [44], which found that female cows aged $>25$ months had the highest number of cases compared to male calves. Because of the length of time animals are exposed to the LSD virus, their chances of becoming infected are growing. The catastrophic of the disease in Holstein-Friesian cattle may be exacerbated by high-yielding cows [45].

TABLE I: PREVALENCE OF LuMPy SKIn DiSEASE BASED ON SEX AND AGE

\begin{tabular}{cccccc}
\hline Gender & $\begin{array}{c}\text { Age } \\
\text { (Years) }\end{array}$ & $\begin{array}{c}\text { Total } \\
\text { Number } \\
\text { examined }\end{array}$ & $\begin{array}{c}\text { Affected } \\
\text { Animals }\end{array}$ & $\begin{array}{c}\text { Animals } \\
\text { Died }\end{array}$ & P-Value \\
\hline Male & $<2$ & 14 & $34.45 \%$ & 1 & \\
& $2-4$ & 10 & $34.43 \%$ & 0 & 0.0023 \\
Female & $>4$ & 5 & $17.24 \%$ & 0 & \\
& $<2$ & 17 & $24.13 \%$ & 2 & \\
& $2-4$ & 32 & $43.1 \%$ & 0 & $<0.0001$ \\
& $>4$ & 9 & $10.34 \%$ & 0 & \\
\hline
\end{tabular}

In our study, young male cattle were also infected, although there was a considerable difference in susceptibility between age groups, with bull calves $(34.45 \%)$ being more susceptible than older bulls $(17.24 \%)$. Biswas et al. [30], revealed $6.73 \%, 48.08 \%$, and $6.73 \%$ in male animals aged 0-12 months, 13-36 months, and (>36) months, respectively, whereas Haque and Gofur showed $14.2 \%$ infected male animals. A substantial percentage of male cattle were infected when male and female cattle were not compared based on age. Male animals were fatigued from heavy work rather than biological work [42], [46]. In addition, draft male animals could not protect themselves well from biting flies while harnessed in the yolk and plowing; biting flies could transmit LSD infection by adhering themselves to the host body at that time [30]. In comparison to the other age groups, both male $(34.45 \%)$ and female $(24.13 \%)$ calves became infected (Table I). Calves housed in close quarters and given extra attention make it through the night without being bitten by insects [47]. However, the majority of farmers lacked the necessary biosecurity training. Farm living conditions were inadequate; sick animals were not isolated in most cases. In natural infection, young calves are more susceptible to the disease and have severe skin lesions owing to low humoral immunity transfer and poor health [48]. The precise reasons, on the other hand, must be determined. The calves' sensitivity to LSDV was increased by rearing them with sick moms, and malnourished calves perished due to the virus.

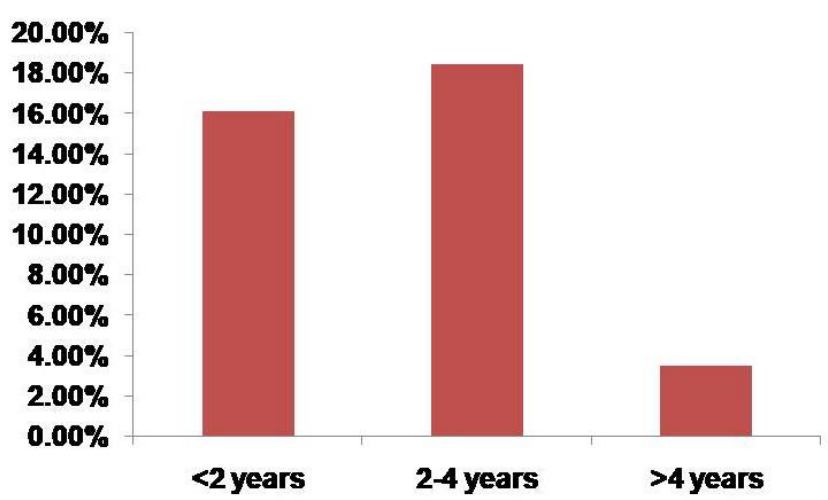

Fig. 2. Incidence of Limb swelling with various age types in infected cattle.

In this study, it was revealed that LSD positive young (24 years) cattle had the highest (18.39 percent) limb swelling, which was distinct from other age groups of $16.09 \%$ for (2) years and $03.45 \%$ for (>4) years (Fig. 2). Biswas et al. noticed that LSD-positive young cattle had the most limb swelling (12.02\%) for (1-3) years [30]. In LSD-infected cattle, limb edema and lameness were also seen, as well as reluctance to move [49]. Lameness may be caused by deep intradermal or intramuscular inflammatory skin nodules that spread to the tendon and tendon sheath, resulting in arthritis [50]. Arthritis and lameness in cattle are sometimes caused by swelling around the joints, cellulitis, or phelgmone [36]. However, some limb swelling may be due to age-related lessons.

Mechanical vectors such as flies and mosquitoes thrive in an environment where intra-herd hygiene and management conditions are poor. According to the findings, poor hygienic management practicing households had a higher percentage of cattle $(48.27 \%)$ infected with LSD than good $(01.14 \%)$ and medium $(26.43 \%)$ hygienic management practicing households (Fig. 3). Biswas et al. found that poor sterile management practices farms had more LSD-infected cattle $(47.54 \%)$ than good $(2.73 \%)$ and medium $(9.29 \%)$ clean management practices farms. [31]. The likely primary cause of viral transmission is poor biosecurity standards, farm waste management, and a high density of biting flies around the feedlot [51].

Intra-herd pest control and poor vaccination have recently been identified as probable causes of LSD spread. However, according to this survey, most cow owners (91.17\%) do not utilize mosquito nets in their cattle houses at night (Fig. 4).

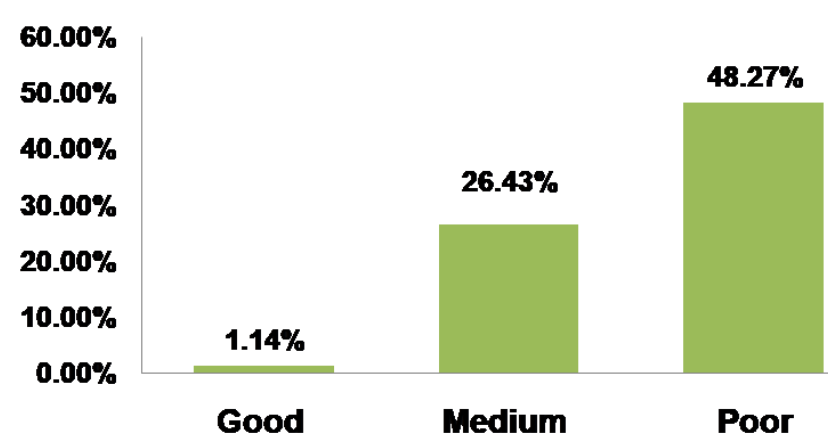

Fig. 3. Impacts of farm hygiene on cattle with the incidence of Lumpy Skin Disease.

Another study by Biswas et al. reported that $97.81 \%$ of cattle owners do not employ mosquito curtains in their livestock houses at night. Mosquito nets, fly repellent 
systems, and smoke generators can protect farm animals from biting flies and mosquitoes [30]. After being bitten by infected insects, the LSD virus multiplied in blood and skin cells until viremia was observed six days later. Skin nodules began to develop on the surface around seven days postinoculation [30]. High viral levels are found in the skin lesions and blood, suggesting that transmission by insects to other healthy animals is possible [30]. LSD, on the other hand, is rarely conveyed through physical contact [52].

\section{Usage of Mosquito Net}

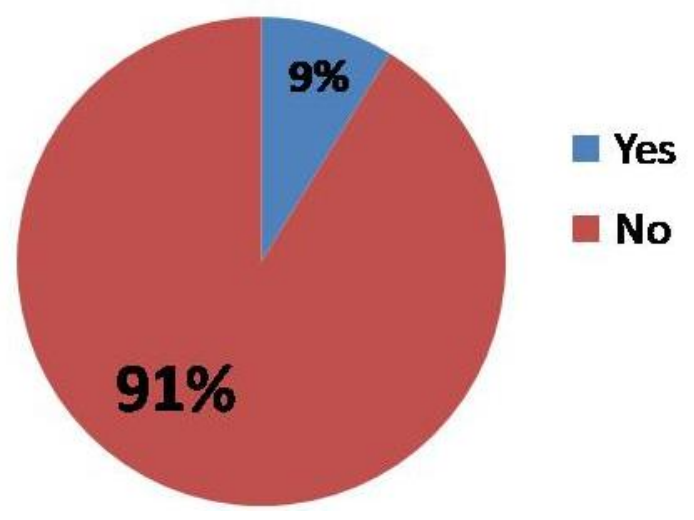

Fig. 4. Usage of mosquito curtains in cattle house at night in the study area.

\section{CONCLUSION}

Female cattle were shown to be the most vulnerable to LSD infection, and most cow owners $(91.17 \%)$ do not use mosquito nets in their cattle houses at night. However, culling all affected animals will not be enough to stop the disease from spreading. As a result, a nationwide awareness campaign should be launched regarding the recently discovered LSD infection in the dairy business.

\section{ACKNOWLEDGMENT}

The authors would like to express their deepest sense of gratitude and sincere thanks to the People's Republic of Bangladesh government, Ministry of Education, and Bangladesh Bureau of Educational Information \& Statistics (BANBEIS), for their financial support for this research work. In addition, Subir Sarker is the recipient of an Australian Research Council Discovery Early Career Researcher Award (grant number DE200100367) funded by the Australian Government.

\section{CONFLICT OF INTEREST}

The authors declare no conflict of interest.

\section{REFERENCES}

[1] Anon. Export products of Ethiopia in all regions. 2009 (http://www.addismillennium.com/majorexportproductsofethiopia2.ht $\mathrm{m})$.

[2] Thornton P.K. Livestock production: recent trends, future prospects. The Royal Society, Sep. 2010; 365: 2853-2867.
[3] FAO. Food and Agriculture Organization of the United Nations, Global animal disease intelligence report. Annual Issue, Nov. 2015; NO. 5.

[4] Haque M.H., Rahman M.M., Miah M.L., Ahmed S., et al. Exploring Antibiotic Resistance Pattern of Escherichia coli, Salmonella spp., and Staphylococcus spp. Isolated from Eggs in Rajshahi. European Journal of Agriculture and Food Sciences, June 2021; 3: 25-30.

[5] Nuruzzaman M., Haque M.H., Sarker S., \& Begum N. Abomasal Nematodes in Goats Slaughtered at Different Abattoir of Thakurgaon District, Bangladesh. J. Sci. Res., Apr. 2012; 4: 491.

[6] Sarker S., Talukder S., Haque M.H., Islam M.H. \&. Gupta S.D. Epidemiological study on foot and mouth disease in cattle: prevalence and risk factor assessment in Rajshahi, Bangladesh. Wayamba Journal of Animal Science, Feb. 2011; 3: 71-73.

[7] Zinnah M.A., Islam M.T., Rahman M.M., Hossain M.T., et al. Standardization of multiplex reverse transcriptionpolymerase chain reaction and typing of foot-and mouth disease virus prevalent in Bangladesh. Bangladesh Journal of Veterinary Medicine, July 2010; 8: $149-155$.

[8] Nuruzzaman M., Haque M.H., Sarker S., Kabir A., Jalil M.A Epidemiological study on stomach worm in goat in Thakurgaon district. J. Bangladesh Soc. Agri. Sci. Technol., Jan. 2010; 7: 21-24.

[9] Davies F.G. Lumpy skin disease, an African capripox virus disease of cattle. Br. Vet. J., Dec. 1991; 147: 489-503.

[10] Abutarbush S.M. Hematological and serum biochemical findings in clinical cases of cattle naturally infected with lumpy skin disease. The Journal of Infection in Developing Countries, Mar. 2015; 9: 283-288.

[11] Sarkar S., Meher M.M., Parvez M.M.M. and Akther M. Occurrences of lumpy skin disease in cattle in Dinajpur sadar of Bangladesh. Res. Agric. Livest. Fish., Dec. 2020; 7: 445-455.

[12] Woods J.A. Lumpy skin disease-A review. Tropical Animal Health and Production, Mar. 1988; 20: 11-17.

[13] Tulman E.R., Alfonso C.L., Lu Z., Zsak L., Sur J.H., et al. The genomes of sheeppox and goatpox viruses. J. Virol., Jun 2002; 76 : 6054-6061.

[14] Kitching R. Vaccines for lumpy skin disease, sheep pox and goat pox. Dev. Biol., 2003; 114: 161-167.

[15] Babiuk S., Bowden T.R., Boyle D.B., Wallace D.B., Kitching R.P Capripoxviruses: an emerging worldwide threat to sheep, goats and cattle. Transbound. Emerg. Dis., Sep. 2008; 55: 263-272.

[16] OIE. World Organization for Animal Health (OIE), Lumpy Skin Disease: Aetiology Epidemiology, Diagnosis, Prevention and Control. International des Epizootics, OIE Terrestrial Manual, 2012.

[17] Limon G., Gamawa A.A., Ahmed A.I., Lyons N.A. and Beard P.M. Epidemiological characteristics and economic impact of lumpy skin disease, sheeppox and goatpox among subsistence farmers in northeast Nigeria. Front. Vet. Sci., Jan. 2020; 7: 8.

[18] Chihota C.M., Rennie L.F., Kitching R.P. and Mellor P.S. Mechanical transmission of lumpy skin disease virus by Aedes aegypti (Diptera: Culicidae). Epidemiology and Infection, Apr. 2001; 126: 317-321.

[19] Lubinga J.C., Clift S.J., Tuppurainen E.S.M., Stoltsz W.H., Babiuk S. et al. Demonstration of lumpy skin disease virus infection in Amblyomma hebraeum and Rhipicephalus appendiculatus ticks using immunohistochemistry. Ticks and Tick-borne Diseases, Mar. 2014; 5 : 113-120.

[20] Salib F.A., Osman A.H. Incidence of lumpy skin disease among Egyptian cattle in Giza Governorate, Egypt. Vet. World, Apr. 2011; 4: 162-167.

[21] Rouby S., Aboulsoudb E. Evidence of intrauterine transmission of lumpy skin disease virus. Vet. J., Mar. 2016; 209: 193-195.

[22] P.C. Irons, Tuppurainen E.S.M., Venter E.H. Excretion of Lumpy Skin Disease Virus in Bull Semen. Theriogenology, Mar. 2005; 63: 1290-1297.

[23] Prozesky L., Barnard B.J.H. A Study of the Pathology of Lumpy Skin Disease in Cattle. Onderstepoort J. Vet. Res., Sep.1982; 49: 167-175.

[24] Al-Salihi K.A. Lumpy Skin disease: Review of literature. Mirror Research. Veterinary, May 2014; 3: 6-23.

[25] Coetzer J.A.W. Lumpy skin disease. In Infectious Diseases of Livestock. Eds, Coetzer J.A.W., and Tustin R.C., Oxford University Press, Cape Town, Southern Africa, 2004; 1268-1276.

[26] EFSA, European Food Safety Authority, "Scientific report on lumpy skin disease II," Data collection and analysis. EFSA J., 2018; 16 e05176.

[27] OIE, "Event summary: Lumpy skin disease, Bangladesh," Available from: https://www.oie., 2019c.

[28] European Food Safety Authority E.F.S.A., Calistri K., DeClercq S Gubbins, Klement E., Stegeman A., Abrahantes J.C., Marojevic D. Antoniou S.E. and Broglia A. Lumpy skin disease epidemiological report IV: Data collection and analysis. EFSA J., 2020; 18: e06010. 
[29] Dhaka Tribune. LSD disease returns: Loss of cattle in rapid contagion worries farmers ahead of Eid. June 24, 2020.

[30] Biswas D., Saha S.S., Biswas S. and Sayeed M.A. Outbreak of lumpy skin disease of cattle in south-west part of Bangladesh and its clinical management. Veterinary Sciences: Research and Reviews, July 2020; 6: 100-108,

[31] Sarkar S., Meher M.M., Parvez M.M.M. and Akther M. Occurrences of lumpy skin disease in cattle in Dinajpur sadar of Bangladesh. Res. Agric. Livest. Fish. Dec. 2020; 7: 445-455.

[32] Tuppurainen E. Evaluation of vector potential of Rhipicephalus appendiculatus, Amblyomma hebraeum and Rhipicephalus decoloratus ticks for lumpy skin disease virus. Helsingin yliopisto, May 2015;13: 225-231.

[33] OIE, "Event summary: Lumpy skin disease, India," Available from: https://www.oie.int/, 2019a.

[34] OIE, "Event summary: Lumpy skin disease, China," Available from: https://www.oie.int/, 2019b.

[35] El-Neweshy M.S., El-Shemey T.M., and Youssef S.A. Pathologic and immunohistochemical findings of natural lumpy skin disease in Egyptian cattle. Pak. Vet. J., 2013; 33: 60-64.

[36] Salib F.A. and Osman A.H. Incidence of lumpy skin disease among Egyptian cattle in Giza Governorate, Egypt. Vet. World, April 2011; 4: $162-167$.

[37] Haque M.N. and Gofur M.R. Investigation of lumpy skin disease outbreak in cattle in Naogaon, Bangladesh. Bangladesh Journal of Agriculture and Life Science, June, 2020; 1: 89-93.

[38] Hasib F.M.Y., Islam M.S., Das T., et al. Lumpy skin disease outbreak in cattle population of Chattogram, Bangladesh. Vet Med Sci. 2021;00: 1-9.

[39] CFSPH, "Center for Food Security and Public Health, Iowa State University," College of Veterinary Medicine, Pp. 55-67, 2011.

[40] Gumbe A.F. Review on lumpy skin disease and its economic impacts in Ethiopia. J. Dairy Vet. Anim. Res., 2018; 7: 39-46.

[41] Tuppurainen E.S.M., and Oura C.A.L. Review: Lumpy Skin Disease: An Emerging Threat to Europe, the Middle East and Asia. Institute for Animal Health, Pirbright, and Surrey, United Kingdom, 2011; 6 : 243-255.

[42] Gari G., Waret-Szkuta A., Grosbois V., Jacquiet P., and Roger F. Risk Factors Associated with observed clinical lumpy skin disease in Ethiopia. Epidemiol. Infect., 2010; 138: 1657-1666.

[43] Kasem S., Saleh M., Qasim I., Hashim O., Alkarar A., et al. Outbreak investigation and molecular diagnosis of lumpy skin disease among livestock in Saudi Arabia 2016. Transboundary and Emerging Diseases, 2018; 65: e494-e500.

[44] Ochwo S., Vander-Waal K., Munsey A., Nkamwesiga J., Ndekezi, C. et al., Seroprevalence and risk factors for lumpy skin disease virus seropositivity in cattle in Uganda. BMC Vet. Res., 2019; 15: 236.

[45] Tageldin M.H., Wallace D.B., Gerdes G.H., Putterill J.F., Greyling R.R., et al., Lumpy skin disease of cattle: an emerging problem in the Sultanate of Oman. Trop. Anim. Health Prod., 2014; 46: 241-246.

[46] Abera Z., Degefu H., Gari G., and Kidane M. Sero-prevalence of lumpy skin disease in selected districts of West Wollega zone, Ethiopia. BMC Vet. Res., 2015; 11: 135.

[47] Magori-Cohen R., Louzoun Y., Herziger Y., Oron E., Arazi, A. et al., Mathematical modelling and evaluation of the different routes of transmission of lumpy skin disease virus. Vet. Res., 2012; 43: 1-13.

[48] Coetzer J.A.W. and Tuppurainen E. Lumpy skin disease. In: Infectious diseases of livestock. Oxford University Press, Southern Africa. 2004; 1268-1276.

[49] Tassew A., Assefa A., Gelaye E., Bayisa B., and Ftiwi M. Identification and molecular characterization of lumpy skin disease virus in East Hararghe and East Shoa Zone, Oromia Regional State. ARC J. Anim. Vet. Sci., 2018; 4: 1-16.

[50] Tuppurainen E.S.M., Babiuk S., and Klement E. Lumpy skin disease. Springer International Publishing AG, 2018; 65-70.

[51] Alemayehu G., Leta S., Eshetu E., and Mandefro A. Incidence of lumpy skin disease and associated risk factors among export-oriented cattle feedlots at Adama District, Central Ethiopia. J. Vet. Med. Anim. Health, 2015; 7: 128-134.

[52] Tageldin M.H., Wallace D.B., Gerdes G.H., Putterill J.F., Greyling R.R. et al. Lumpy skin disease of cattle: an emerging problem in the Sultanate of Oman. Trop. Anim. Health Prod., 2014; 46: 241-246.

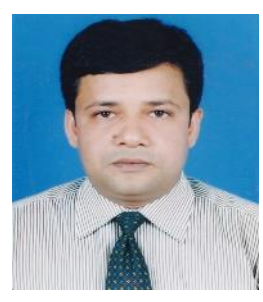

Dr. Md. Hakimul Haque is an Associate Professor in the Department of Veterinary and Animal Sciences, Faculty of Agriculture at the University of Rajshahi, Bangladesh. Dr. Haque completed DVM from Bangladesh Agricultural University (BAU) in 2005. Later he completed a Master of Science (MS) in Microbiology from the BAU in 2007 and received a $\mathrm{PhD}$ from the school of Medicine in collaboration with the School of natural science and Queensland Micro and Nanotechnology Centre, Griffith University in 2017 and a Postdoc from the Griffith University and University of Wollongong, Australia.

Dr. Haque's research has initially focused on bacteria, viruses, fungus, and parasites, to comprehend the impacts of disease damage to agricultural industries. He has worked on epidemiological, serological, and molecular characterization of bacterial, parasitic, and viral pathogens. This work is published in 28 journals at the national and international level. In his $\mathrm{PhD}$ work, he identified several biomarkers and established their relationship for clinical and pathological use in diagnosing oesophageal squamous cell carcinoma. Subsequently, he has developed novel electrochemical and nanotechnology-based diagnostic biosensor platforms using Gold-DNA and Graphene-DNA affinity interactions. This work resulted in several Q1 and Q2 journal publications focused on multidisciplinary research. As a research team leader, Dr. Haque has worked as a supervisor and cosupervisor for $10 \mathrm{MS}$ and $\mathrm{PhD}$ students. 